\title{
ESTIMATION OF DESTRUCTION OF MISSILE WITH CUMULATIVE HEAD DURING CONTACT WITH CHOSEN TYPE OF ROD ARMOUR
}

\author{
K. SYBILSKI, R. PANOWICZ, T. NIEZGODA \& W. BARNAT \\ Department of Mechanics and Applied Computer Science, Military University of Technology, Poland.
}

\begin{abstract}
This is an extended paper of an original published in the Computational Methods and Experimental Measurements 2011 conference proceedings.
\end{abstract}

\begin{abstract}
Military operations performed by UN and NATO forces within the framework of stabilization missions revealed the weak points of the equipment utilized by these organizations. It turned out that one of the most dangerous threats is posed by partisan missiles equipped with cumulative heads. These missiles are mostly based on a Soviet solution and allow the penetration up to $300 \mathrm{~mm}$ of reinforced steel. This fact results in a serious problem which concerns the relevant protection against such a type of weapon. One of protection methods against cumulative missiles is the application of rod armours.

The present paper concentrates on the analysis of the impact of a missile with a cumulative head (type PG-G7) into armour made of rods with a circular cross-section. Four options of rods arrangements were considered. A short characteristic of an analysed object was presented. A principle of operations of a missile with the specification of its sensitive elements was described from the perspective of originating of a cumulative stream. The stages of constructing a numerical model as well as the applied simplifications of geometry and initial boundary conditions were presented. On the basis of the obtained results, a degree of destruction of key elements of the missile was estimated. The figures revealing deformation of the missile and the maps of stresses in these elements were presented. In the summary section, an influence of a degree of the impact of a missile type PG-G7 into an armour made of rods with circular cross-section on weakening of operation effectiveness of such type of ammunition was determined.

The calculations were realized in LS-Dyna system which is purposed, among others, for fast changing analyses with the use of a finite element method. To solve an equation of motion, an explicit integration method included in this system was applied.
\end{abstract}

Keywords: Finite element method, mechanics, rods armour, RPG.

\section{INTRODUCTION}

As a result of armed conflicts observation all over the world and operations carried on by UN and NATO divisions within a framework of stabilization missions, there can be noticed a change in the way of fighting and the usage of available ammunition. It appears that currently the most serious threat is posed by two types of ammunition. The first one is the kinds of landmines and improvised explosive devices (IED), whose basic destructive factor is a pressure wave formed as a result of explosion of explosive material. The destruction effect is multiplied by all kinds of shrapnel (marbles, nails, screws, etc.) placed inside or on the explosive device. The second group of the most threatening ammunition comprise bullets with cumulative heads. Due to their high penetration (reaching $900 \mathrm{~mm}$ of reinforced steel RHA [1]), low production cost and the simplicity of use, they are mainly used to destroy military armoured vehicles as well as objects of strategic importance. Such objects frequently include: buildings, reinforced positions of army stationing and even low-flying aircrafts.

High penetration of cumulative missiles results in the fact that protection against such a type of weapon constitutes a serious problem. One of the protection methods against cumulative missiles is application of rod armours. Their advantage is a simple construction and 
relatively small mass. The armours of this type are not purposed for stopping a missile but only for neutralizing a conical liner and explosive material inside the missile.

This paper presents an analysis of impact of a missile with a cumulative head (type PG-7G) into a rod armour arranged under different angles. On the basis of the enclosed results, the analysis of effectiveness evaluation will be carried out.

\section{CONSTRUCTION OF A MISSILE AND PRINCIPLE OF ITS OPERATION}

The unquestionable advantages of the PG-7G missile discussed in the paper are small gauges [2] (length - approximately $900 \mathrm{~mm}$, diameter - up to $85 \mathrm{~mm}$ ) and small mass (approximately $2 \mathrm{~kg}$ ), which enables its easy transportation and hiding.

The missile consists of three basic elements: warhead, rocket motor and flight stabilizer (Fig. 1). The warhead consists of: body, ballistic cap, conical liner, high explosive charge, wave shaper, conductive cone, isolator and fuse.

During shooting, the missile PG-7G is fired from a hand grenade launcher with the use of a rocket engine (the maximum speed obtained by a missile is approximately $300 \mathrm{~m} / \mathrm{s}$ ) and in the end it hits the target. In the moment of the impact on the target, the fuse generates an electrical impulse which stimulates explosive material by a detonator. The electrical impulse is transmitted by two circuits: inner and outer. The outer circuit consists of a ballistic cap and a warhead body. The inner circuit consists of a conductor and a conical liner. Detonation of explosive material results in originating of a cumulative stream. The explosive material must

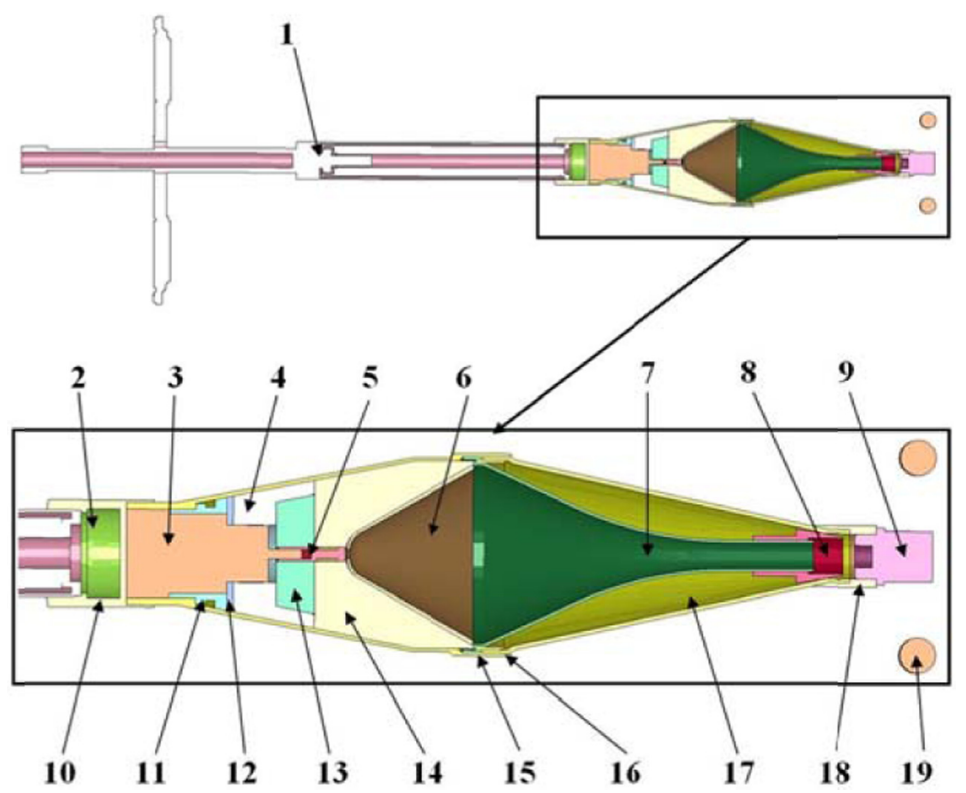

Figure 1: Head intersection of PG-7G; 1 - rocket motor, 2 - jets of rocket motor, 3 - fuse base assembly, 4 - high explosive charge-bottom cube, 5 - conductor, 6 - conical liner, 7 - conductor, 8 - isolator, 9 - head part of fuse, 10 - warhead body, 11 - arranging element, 12 - roller, 13 - wave shaper, 14 - high explosive charge - upper cube, 15 - isolator, 16 - ring, 17 - nose, 18 - element fixing the upper part of fuse, 19 - rod armour. 
be properly formed to obtain the correct orientation and energy concentration. The optimal consists in making a conical niche in its front part with an opening angle of approximately $60^{\circ}$. To increase efficiency of such a charge, inserts made of different kind of materials, for example, copper, are placed into the niche.

The originated cumulative stream constitutes approximately $20 \%$ of conical liner mass and moves with velocity of a few kilometres per second along the charge symmetry axis. The rest of material originates a so-called cluster moving with relatively small velocity. The cumulative stream is in the form of a thin metal thread with the thickness of few millimetres in the widest point. It is the factor responsible for destructions. During the impact into an armour, a hole of depth up to 9 calibres of the insert is created.

An important factor connected with the effectiveness of the missile is the precision of its execution. To get a cumulative stream originated, the explosive material and the conical liner must be manufactured very accurately. To obtain the maximum destructive force, inaccuracy of executing the system should not exceed $0.05 \mathrm{~mm}$ and $0.03 \mathrm{~mm}$ in the case of radius deviation of the insert. If these requirements are not fulfilled, the effect of missile operating will be more minor. In an extreme case, at a very significant inaccuracy, the destructive force of the missile will be comparable to detonation of explosive material corresponding to the mass of the charge contained in the head.

The above condition of accuracy of executing a missile uses rod armour. Explosive material and an insert in the missile should be subject to the largest deformations and damages. In the case of a very strong deformation of these elements, detonation of explosive material will not cause origination of the cumulative stream.

An important aspect of rod armours is the width of rods and their spacing. The armour of this type is effective when a fuse is placed between the rods in the moment of missile contact with the armour. Any impact into a fuse, before destructing the cumulative insert and explosive material, will lead to generation of the factor responsible for destruction.

\section{CONSTRUCTION OF A NUMERICAL MODEL}

To conduct the analysis of the impact of PG-7G missile into a rod of circular cross-section, a numerical model representing missile operations was developed. The principal restriction during its construction was the minimum number of used elements, simultaneously maintaining physical behaviour of the model. The purpose of this operation was to shorten the time of solving the whole task, what gives the opportunity to analyse several options of calculations in relatively short time. Limitation of elements number was possible due to application of geometry simplifications (Fig. 2) which do not affect behaviour of the system as a whole.

Five main simplifications were introduced into the model:

1. The shoulders and a hole in the tube located between the nozzles and the fins were removed.

2. The flight stabilizer was replaced by a cylinder with identical mass.

3. The holes fastening the fins were removed.

4. The nozzles were removed.

5. A part of the fuse protruding outside the missile was replaced with one cylinder.

Additionally, all the parts located behind the nozzles were treated as one part attributed with material properties allowing reflection of the real inertial mass parameters of the replaced parts. 


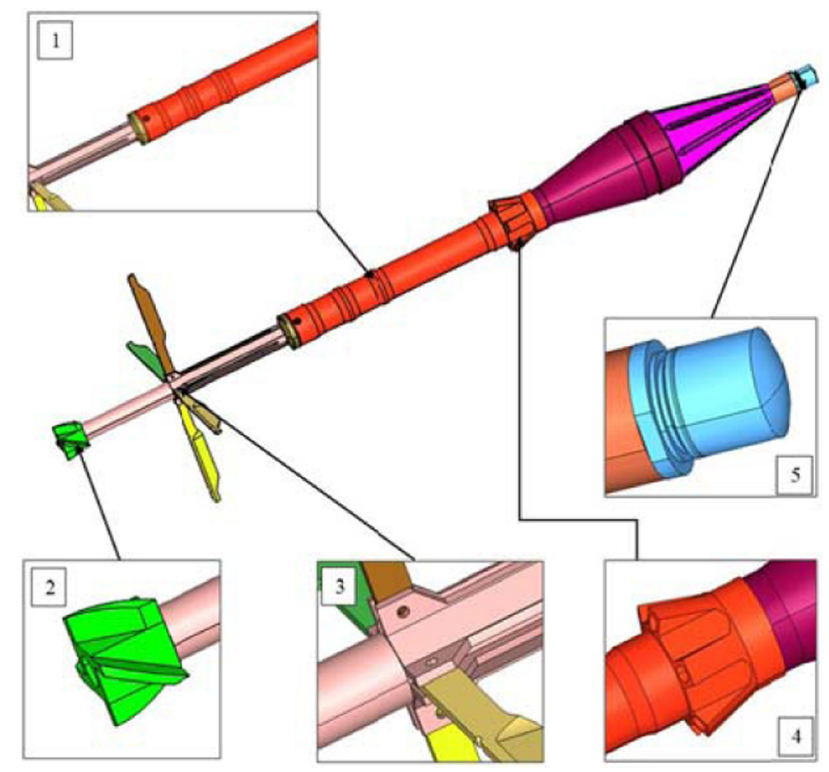

Figure 2: Missile geometry simplifications.

The final numerical model is composed of 19 parts (Fig. 1), which were constructed from 106,484 finite elements. Material properties attributed to particular parts correspond to materials used in reality. To describe the behaviour of materials, two models were used: Piecewise_Linear_Plastic and Simplified Johnson-Cook. First of them was applied by using the graph of stresses in the function of deformations to all the parts, except those made of copper. The Johnson-Cook model was used to describe copper.

In the numerical model, all the parts located inside the head as well as the phenomenon of contact with friction between them were taken into consideration. The procedure of contact was realized by an Automatic_single_surface type model applied mostly in analyses of a crash-type due to the fast changing displacement of elements and large deformations. Additionally, Contact_automatic_surface_to_surface_tiebrak type contacts between the head and the ballistic cap were defined. Owing to this fact, the partial mapping of thread joint between these parts was possible by introducing the possibility of conditional separation of the joined elements.

\section{INITIAL-BOUNDARY CONDITIONS}

During the analysis, the previously developed numerical model of PG-7G type missile [3] was completed with a rod armour. The armour consisted of round rods with diameter of 15 $\mathrm{mm}$ and length of $500 \mathrm{~mm}$ distant from each other by $83 \mathrm{~mm}$ (Fig. 3). St3S steel was accepted as rod material.

During numerical simulation, four rods arrangements were analysed. In the first case, the impact at the right angle in relation to the plane created by rods axes (Fig. 3) was considered. In the second case, the rods were rotated by the angle of $30^{\circ}$ in relation to the axes coming through the centres of the rods (Fig. 4). In the third case, the rods arranged in compliance with the first case were rotated by the angle of $30^{\circ}$ in relation to the axis parallel to the rods axis (Fig. 5). The fourth analysed case is a combination of the second and third cases. 


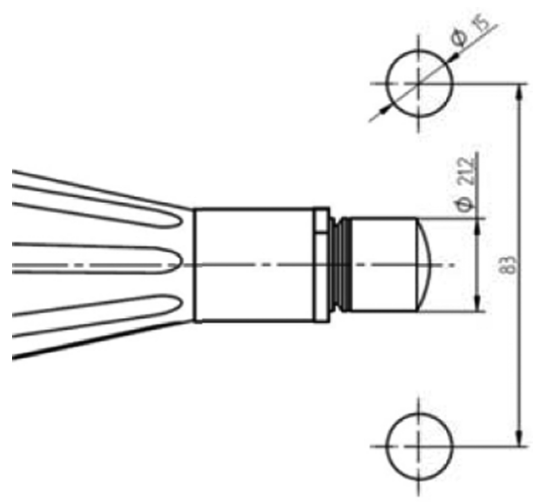

Figure 3: First case of impact.

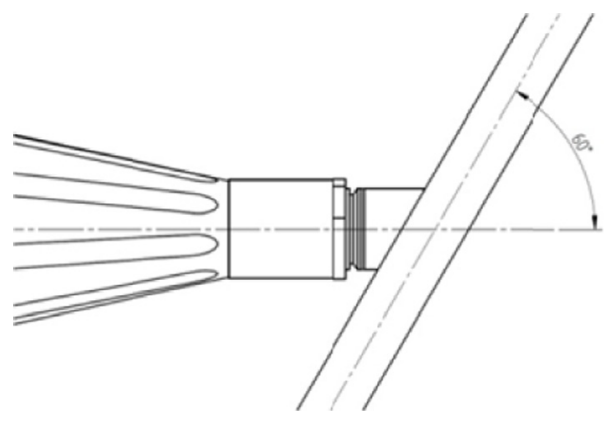

Figure 4: Second case of impact.

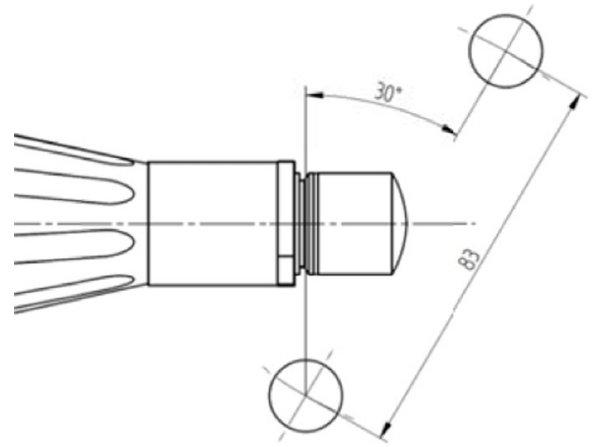

Figure 5: Third case of impact.

In all the analysed arrangements, all degrees of freedom of the rods ends were taken away (Fig. 6). Moreover, in each option, the most advantageous, from the perspective of missile neutralization, the case of impact was taken into account: in the middle of the rods length, exactly between them. In the case of the asymmetrical impact, larger deformations of the important elements of the considered system occur, although it takes place only on one side.

The missile velocity in the moment of contact with the armour amounted to $300 \mathrm{~m} / \mathrm{s}$. 


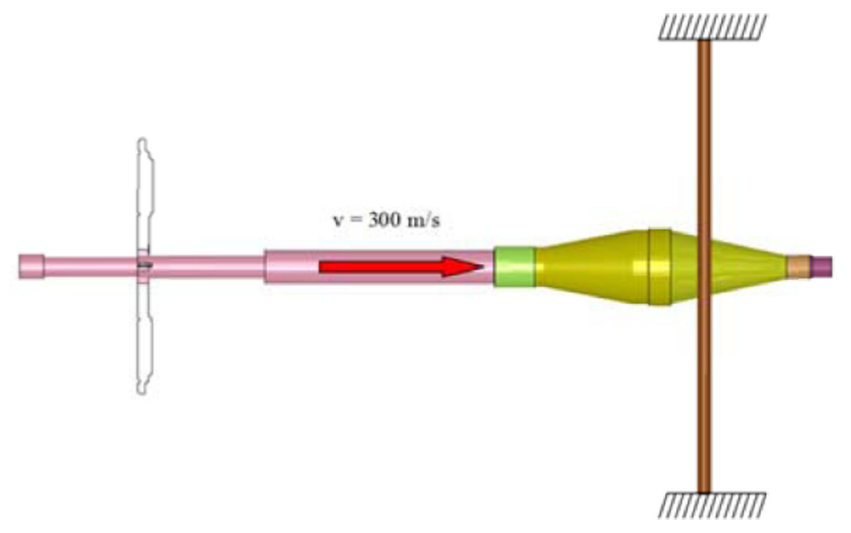

Figure 6: Boundary condition.

\section{ALGORITHM OF SOLVING THE EQUATION OF MOTION}

All the calculations were realized with the use of LS-Dyna solver. This solver is purposed for calculations of the strong nonlinear and dynamic problems with the use of a finite element method. On the base of information included in a numerical model, a dynamic equation of motion is developed in the form of eqn (1) $[4,5]$ :

$$
M \ddot{q}+C \dot{q}+K q=f
$$

where $M-$ inertia matrix,

$C$ - damping matrix,

$K$ - structure stiffness matrix,

$q$ - vector of generalized displacements of nodes of a calculation model and

$f$ - vector of load forces reduced to model nodes.

Matrixes $M, K$ and vector $f$ are determined in the node systems of coordinates by matrix elements aggregation. A damping matrix $C$ is often defined as a function dependent on an inertia matrix and a stiffness matrix:

$$
\mathrm{C}=\alpha M+\beta K
$$

where $\alpha, \beta-$ are constant coefficients.

Besides natural damping resulting from the resistances of the centre and inner fiction, the so-called local damping can occur in a number of constructions. It originates in the constructional joints or it is induced by placing proper damping elements. Moreover, some elements of significant mass with very small volume and elastic elements of negligibly small mass can occur in the construction. The examples of such elements can be springs or dampers. During constructing and describing the model, it is possible to introduce damping and elastic massless elements as well as concentrated masses. Damping and elastic elements are defined by two nodes and coefficients characterizing damping and stiffness at a given degree of freedom (translational and rotational) Elastic and damping elements can be combined in one elasticdamping element defined by the same nodes and a respectively determined resultant value of the damping and elasticity coefficients.

Concentrated masses located in the nodes of the computational model are characterized by their values as well as mass inertia moments determined in respect to the axis of the nodal system. Introduction of elastic and damping elements and concentrated masses into the 
computational model leads to generalizing the elements of the equations of motion which in the generalized form are written as

$$
\begin{aligned}
& M=\Sigma M^{e}+\tilde{M} \\
& K=\Sigma K^{e}+\tilde{K} \\
& C=a M+\beta K+\tilde{C}
\end{aligned}
$$

where: $\tilde{M}$ - matrix of concentrated masses,

$\tilde{K}-$ matrix of stiffness of massless elastic elements and

$\tilde{C}$ - matrix of local damping.

The equation of motion ultimately can be written in the form:

$$
\left(\Sigma M^{e}+\tilde{M}\right) \ddot{q}+(\alpha M+\beta K+\tilde{C}) \dot{q}+\left(\Sigma K^{e}+\tilde{K}\right) q=f .
$$

The equation can be completed with the initial conditions determined in the moment of the simulation beginning $t_{0}$ :

$$
q\left(t=t_{0}\right)=q_{0}, \dot{q}\left(t=t_{0}\right)=\dot{q}_{0} .
$$

Next, the determined integration equation is integrated to determine displacements of the particular nodes of the model. Integration in LS-Dyna software is performed according to the method of direct integration which is also called as 'step by step' method. It is applied to the equations which were not subject to any transformations.

A method of direct integration is based on two assumptions. First of them states that the equation of motion is to be satisfied only in the time moments ' $t$ ' between which there is a certain time interval called an integration step $\Delta t$. It signifies that only the presupposed moments are considered.

$$
0, \Delta t, 2 \Delta t, \ldots t, t+\Delta t, \ldots, T
$$

where $\Delta t$ - integration step,

$t$ - selected time moment and

$T$ - the end of integration range.

According to the second assumption, a changeability character of displacements, velocities and accelerations are presupposed. It means that integration of the equation of motion is reduced to searching the solution in moments $t_{0}+i \Delta t$ by using the known values of the function in previous moments $t_{0}, t_{0}+\Delta t, \ldots, t_{0}+(i-1) \Delta t$. Values of displacements, velocities and accelerations in moment $t_{0}$ are known and result from the initial conditions; however, in the further integration steps, they change according to the form:

$$
\begin{aligned}
& \dot{d}_{t} \cong \frac{1}{2 \Delta t}\left(-d_{t-\Delta t}+d_{t+\Delta t}\right) \\
& \ddot{d}_{t} \cong \frac{1}{\Delta t^{2}}\left(d_{t-\Delta t}-2 d_{t}+d_{t+\Delta t}\right) .
\end{aligned}
$$

After substituting the integration operators into the equation of motion, it takes the form:

$$
\begin{aligned}
\frac{1}{\Delta t^{2}}\left(d_{t-\Delta t}-2 d_{t}+d_{t+\Delta t}\right)\left(\Sigma M^{e}+\tilde{M}\right) & +\frac{1}{2 \Delta t}\left(-d_{t-\Delta t}+d_{t+\Delta t}\right)(\alpha M+\beta K+\tilde{C}) \\
& +\left(\Sigma K^{e}+\tilde{K}\right) d_{t}=P_{t} .
\end{aligned}
$$


The displacements in moment $t+\Delta t$ or $d t+\Delta t$ are determined from the equations above.

A method of direct integration is conditionally stable; therefore, a method of small integration steps $\Delta t$ is required to be applied while calculating the displacements in the subsequent time moments. An integration step has to satisfy the Courant-Friedrichs-Levy condition:

$$
\frac{u \cdot \Delta t}{\Delta x} \leq C \Rightarrow \Delta t \leq \frac{C \cdot \Delta x}{u}
$$

As a result of integration of equation of motion, the values of displacements, velocities and accelerations of particular nodes are obtained. Values of parameters at any point of the model are interpolated on the basis of the values in the nearest nodes.

\section{RESULTS OF ANALYSES}

Figures 7, 8, 9, 10 present the stages of deformation of a missile occurring as a result of impact into the rods arranged according to the first option of the calculations. Symmetrical destruction of the missile is noticed on them. At the initial stage of the analysis, a ballistic cap is destroyed on the radial direction (Fig. 8) causing, as a consequence, rods to strike into the edge of the warhead body. This impact results in slight folding of the warhead body material and its penetration inside the missile. An effect accompanying these processes is breaking of the thread joint between the ballistic cap and head body thereby unsealing the missile.

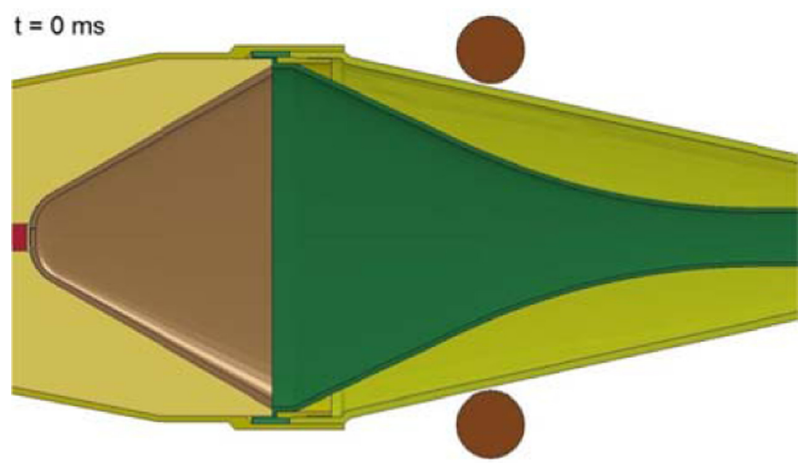

Figure 7: Deformation of the missile for time $t=0 \mathrm{~ms}$.

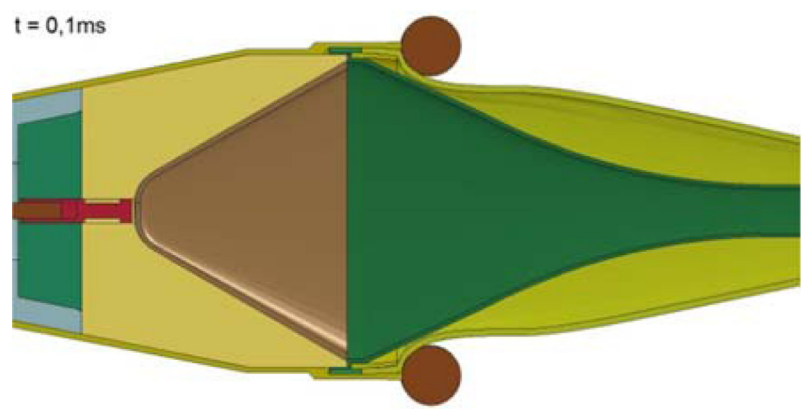

Figure 8: Deformation of the missile for time $t=0,1 \mathrm{~ms}$. 


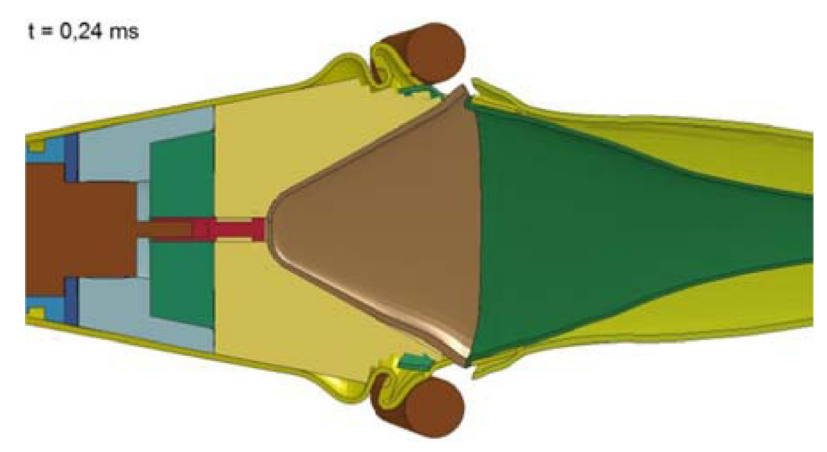

Figure 9: Deformation of the missile for time $t=0,24 \mathrm{~ms}$.

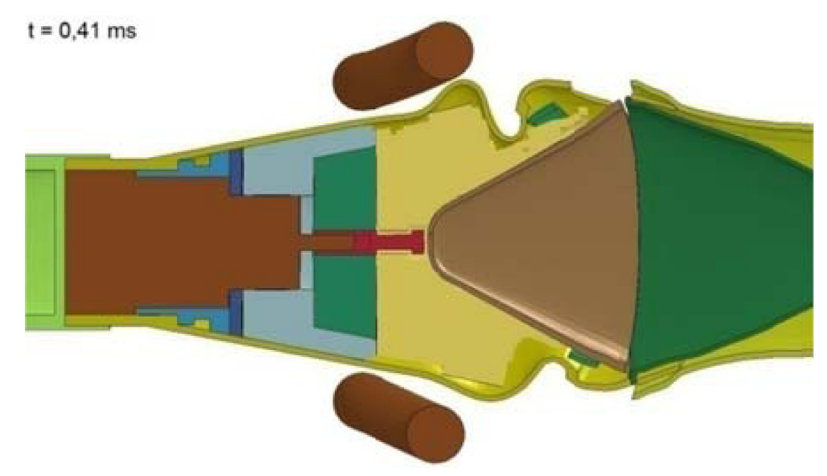

Figure 10: Deformation of the missile for time $t=0,41 \mathrm{~ms}$.

The destruction manner of a missile is reflected in deformation of the cumulative insert as well as in explosive material crushing. Figures $11,12,13$ present explosive material and a conical liner in the subsequent time steps. The final effect is presented in Fig. 13. It shows slight declination of a collar of the conical liner and significantly important crushings of explosive material (approximately $28 \%$ of material volume is subject to crushing).

In the second option of the analysis, the destruction process runs more modestly than in the first one. The ballistic cap is hit in the same way; however, there is no impact into the edges of body head but what results in fact is that the folding on its surface is significantly slighter. This effect is caused by missile partial sliding along the rods during which the rods are drawn apart. It causes enhancement of the clearance between them before the collision with the body takes place.

More modest run of missile destruction is reflected in deformation and destruction of its key elements from the perspective of cumulative steam originating. In the case of a conical liner, its deformations are very similar to the deformations observed in the first option. However, crushing of explosive material is significantly slighter and amounts to approximately $14.5 \%$ of the volume.

The significant difference in the destruction of the missile can be observed in the third option where the rods were rotated in respect to the horizontal axis. The missile cross-section for the subsequent time moments of the analysis is presented in Figs 20, 21, 22, 23, 24. Figure 21 demonstrates that in the moment of contact of the rod with the ballistic cap, the lower rod hits 


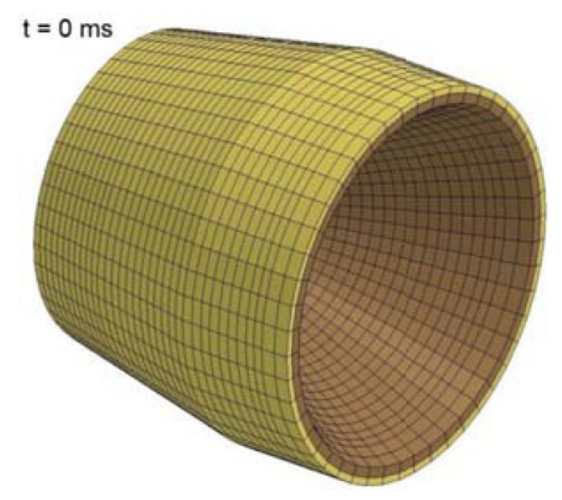

Figure 11: Deformation of the conical liner and the destruction of the explosive material for time $t=0 \mathrm{~ms}$.

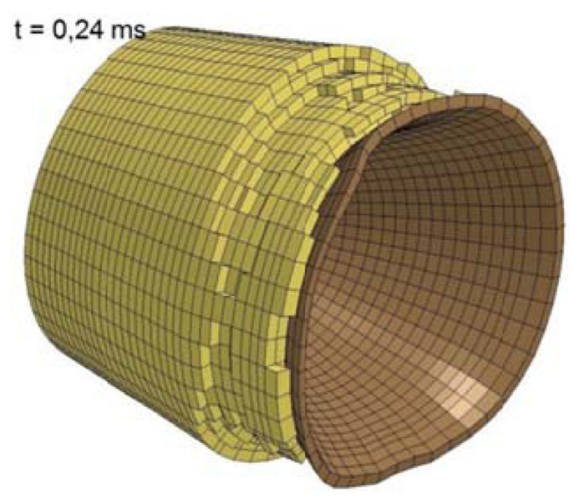

Figure 12: Deformation of the conical liner and the destruction of the explosive material for time $t=0,24 \mathrm{~ms}$.

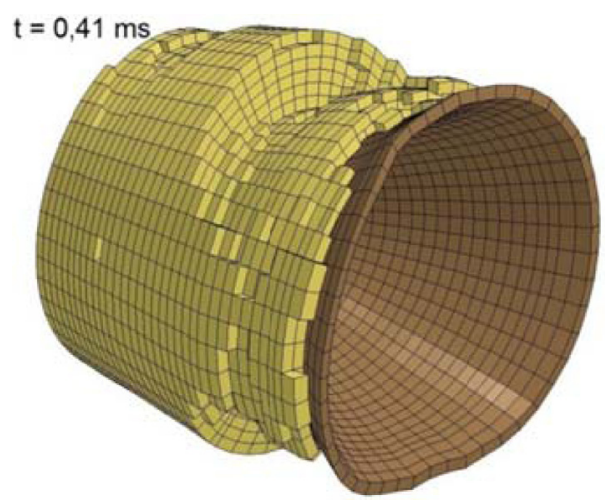

Figure 13: Deformation of the conical liner and the destruction of the explosive material for time $t=0,41 \mathrm{~ms}$. 


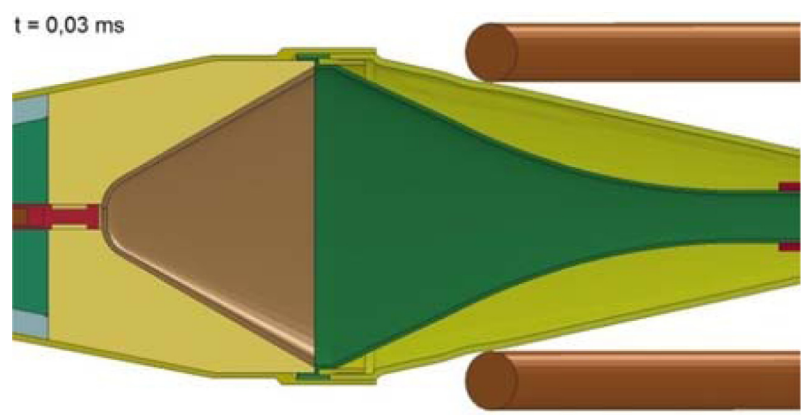

Figure 14: Deformation of the missile for time $t=0,03 \mathrm{~ms}$.

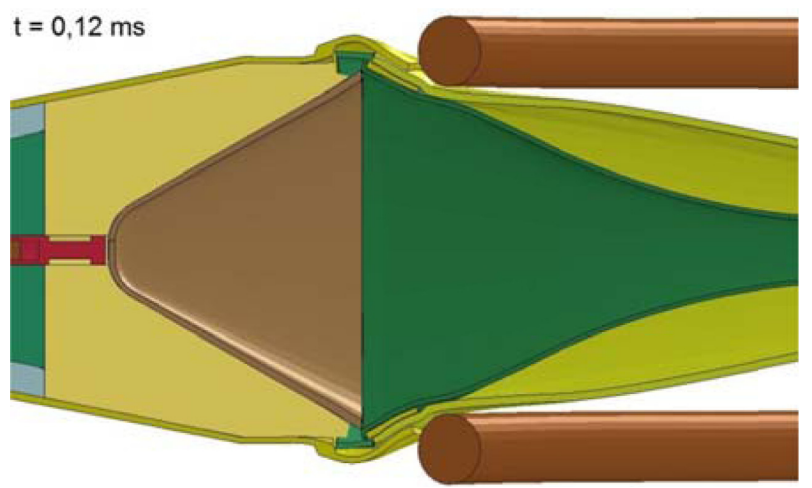

Figure 15: Deformation of the missile for time $t=0,12 \mathrm{~ms}$.

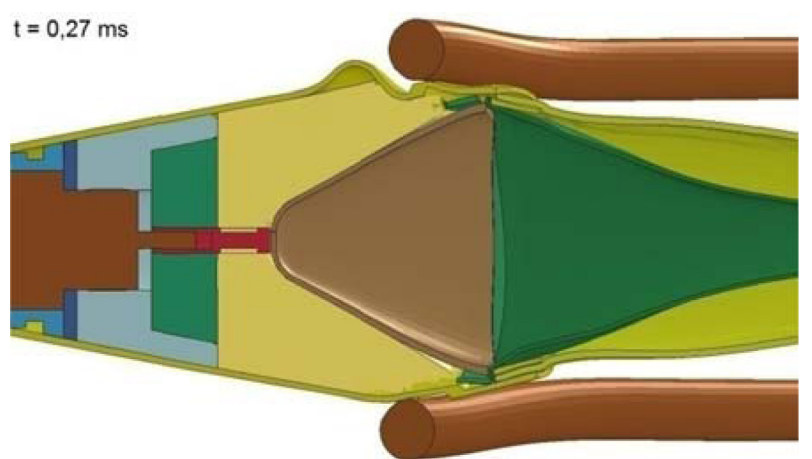

Figure 16: Deformation of the missile for time $t=0,27 \mathrm{~ms}$.

into the edge of the warhead body. Such asymmetrical impact causes displacement of the missile in direction of the upper rod thereby changing its trajectory. Figure 23 shows a completely broken joint of these in respect to each other in the vertical plane. This displacement is a cause of strong penetration of the warhead body material into the inside of the missile (in its upper part) in the further stage of the considered phenomenon run. 


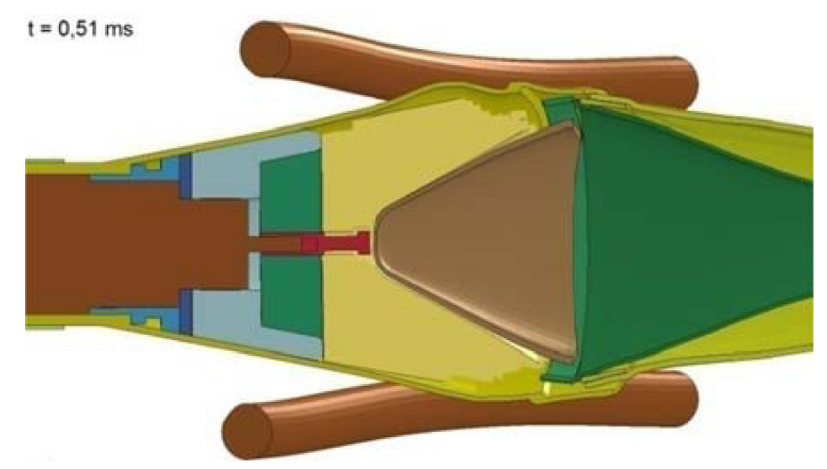

Figure 17: Deformation of the missile for time $t=0,51 \mathrm{~ms}$.

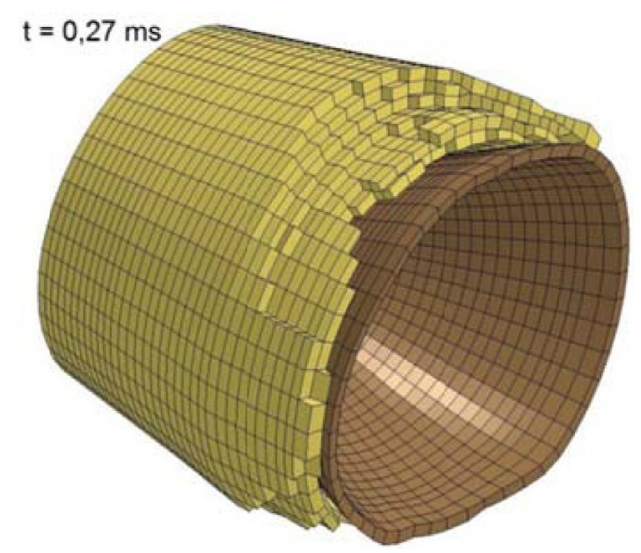

Figure 18: Deformation of the conical liner and the destruction of the explosive material for time $t=0,27 \mathrm{~ms}$.

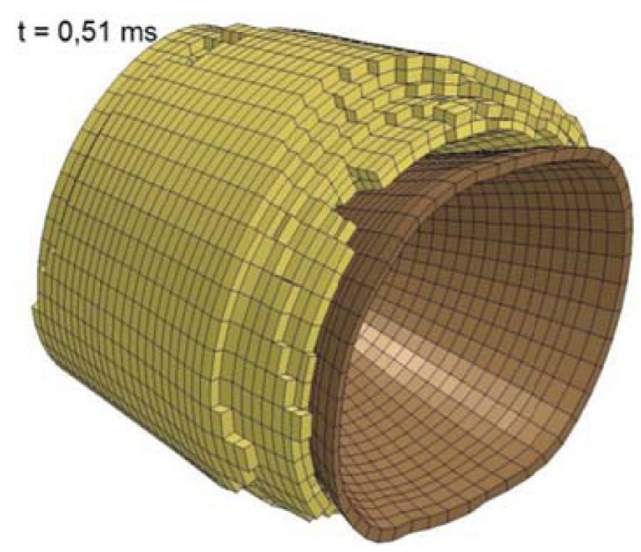

Figure 19: Deformation of the conical liner and the destruction of the explosive material for time $t=0,51 \mathrm{~ms}$. 


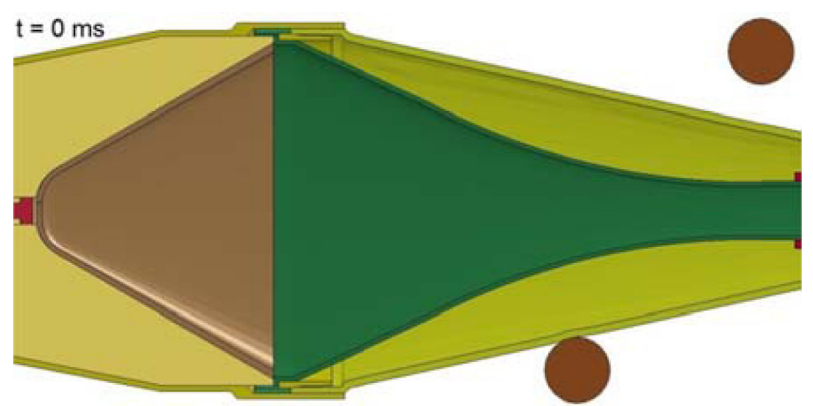

Figure 20: Deformation of the missile for time $t=0 \mathrm{~ms}$.

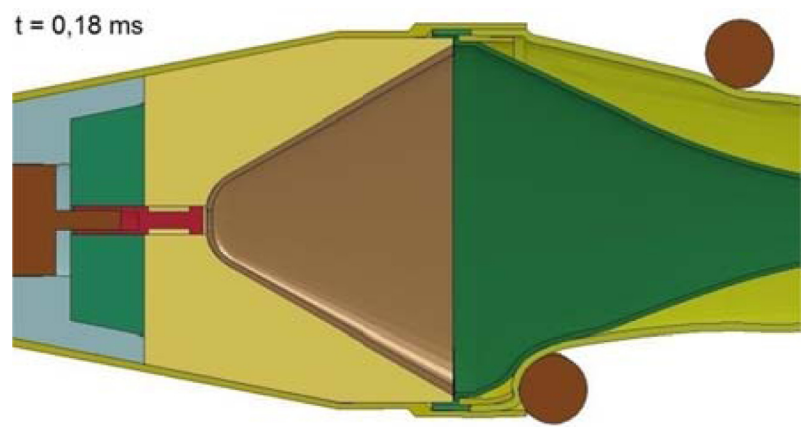

Figure 21: Deformation of the missile for time $t=0,18 \mathrm{~ms}$.

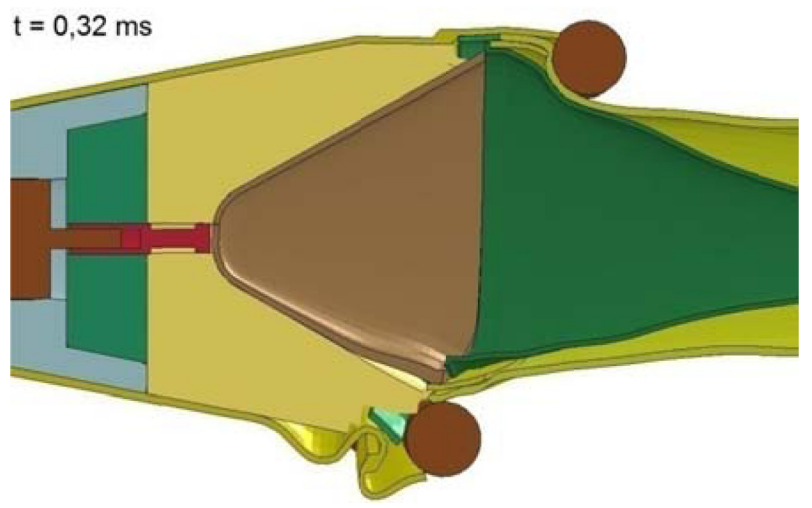

Figure 22: Deformation of the missile for time $t=0,32 \mathrm{~ms}$.

Figures 25, 26, 27 present the explosive material and the conical liner for the subsequent time moments of the analysis of the impact of the missile into the rods arranged according to the third option. The final effect of displacement of both the elements is shown in Fig. 27. In the case of a conical liner, its deformations are very large and symmetrical. The crushings of the explosive material obtained approximatelly $67 \%$ of the volume and it is also very non-symmetric. 


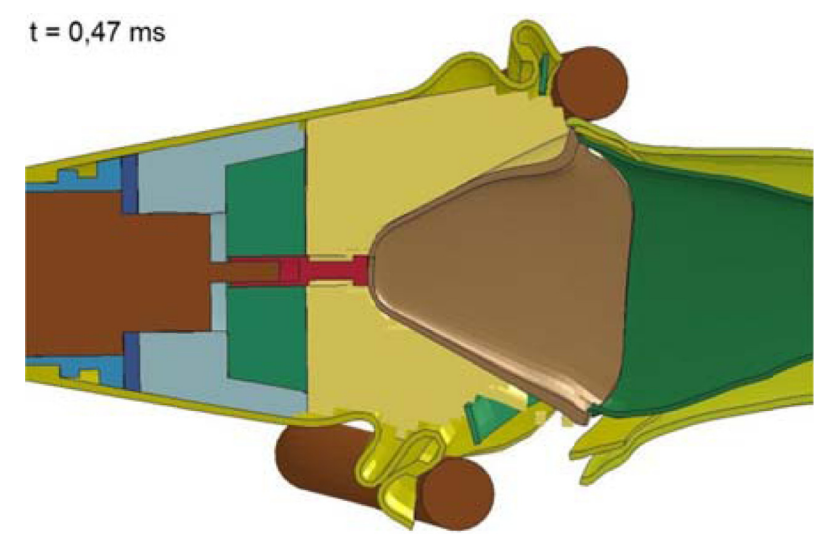

Figure 23: Deformation of the missile for time $t=0,47 \mathrm{~ms}$.

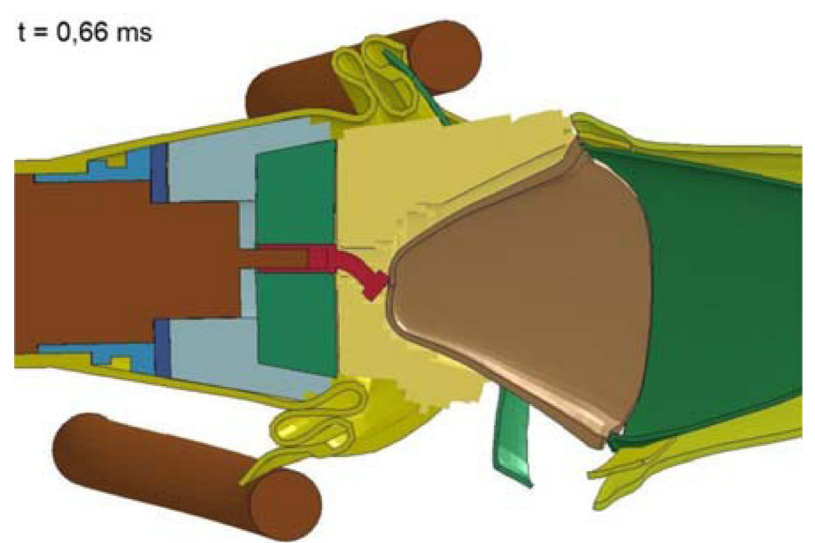

Figure 24: Deformation of the missile for time $t=0,66 \mathrm{~ms}$.

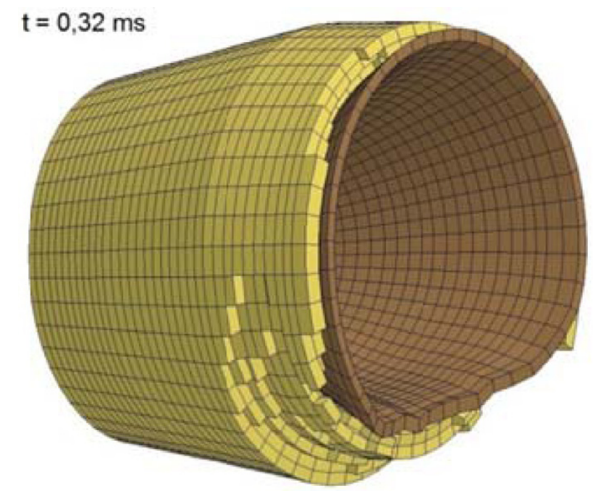

Figure 25: Deformation of the conical liner and the destruction of the explosive material for time $t=0,32 \mathrm{~ms}$. 


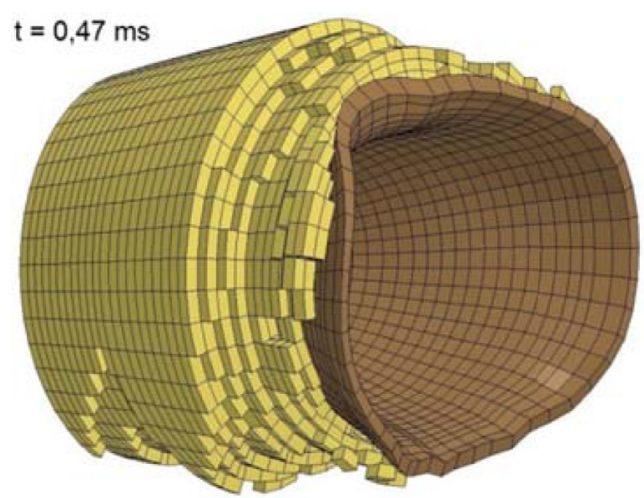

Figure 26: Deformation of the conical liner and the destruction of the explosive material for time $t=0,47 \mathrm{~ms}$.

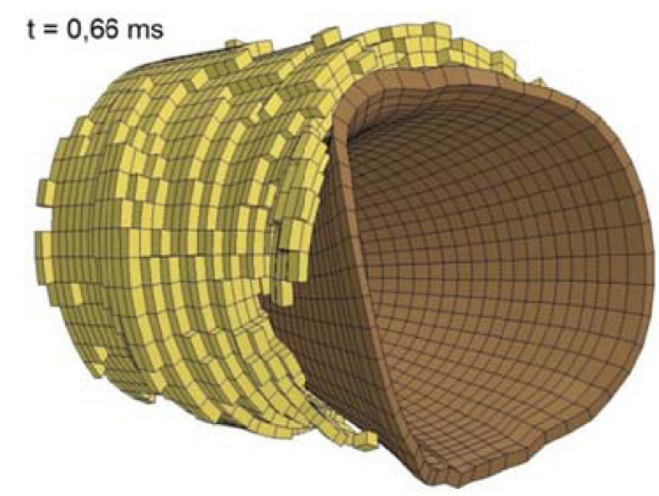

Figure 27: Deformation of the conical liner and the destruction of the explosive material for time $t=0,66 \mathrm{~ms}$.

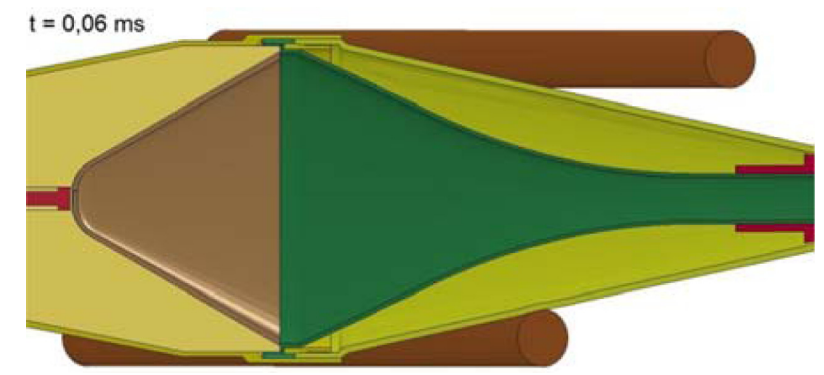

Figure 28: Deformation of the missile for time $t=0,06 \mathrm{~ms}$.

The last analysed option was a combination of rods arrangements from options 2 and 3 . Figures 28, 29, 30, 31, 32 presents the results of the analyses for this case in the subsequent time moments. Figure 30 shows very strong deformation of the conical liner and the head body. Figures 31 and 32 demonstrate progressive folding of the head body and its penetration into the inside of the missile. 


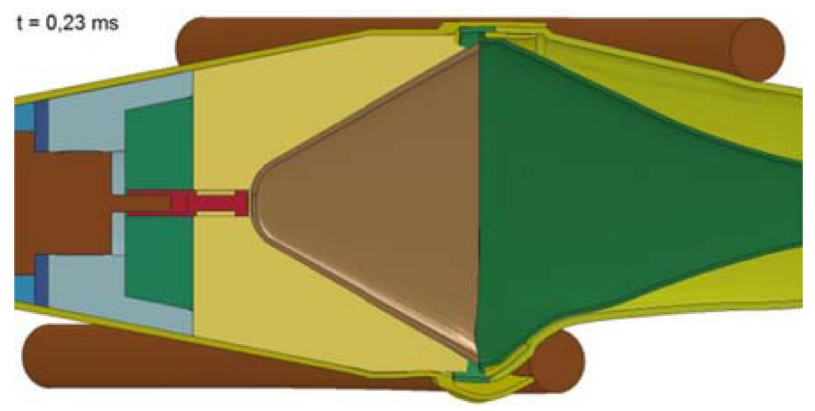

Figure 29: Deformation of the missile for time $t=0,23 \mathrm{~ms}$.

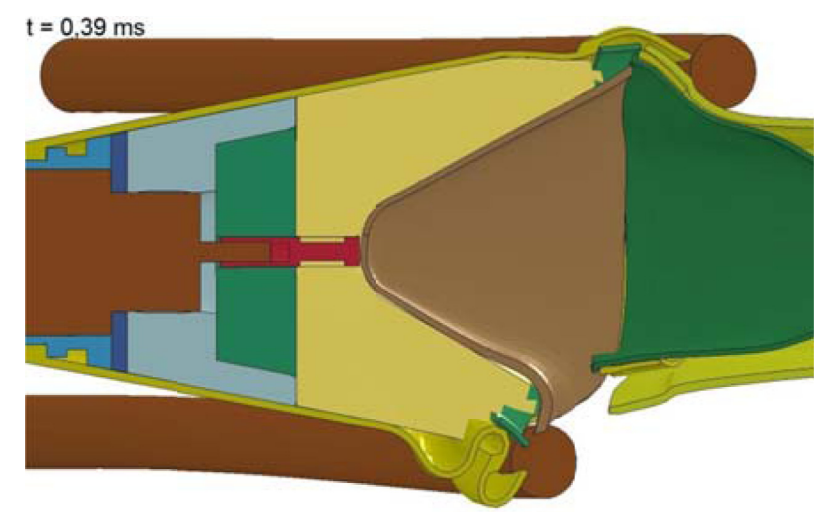

Figure 30: Deformation of the missile for time $t=0,39 \mathrm{~ms}$.

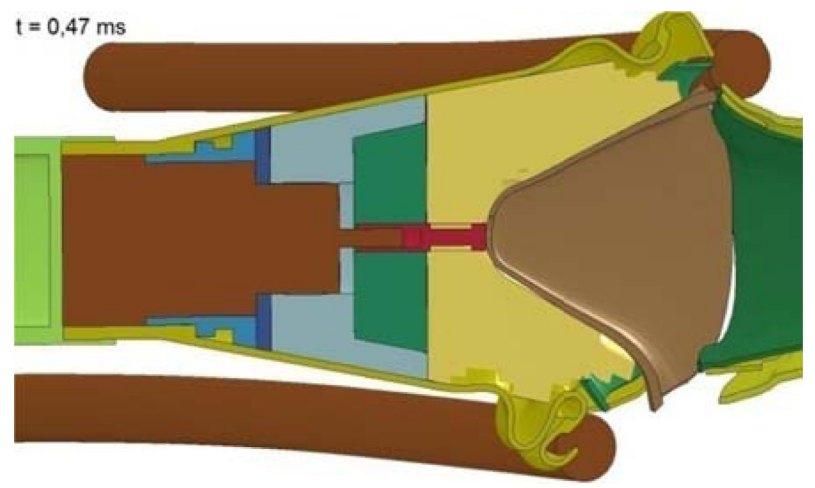

Figure 31: Deformation of the missile for time $t=0,47 \mathrm{~ms}$.

Figures 33, 34, 35 present a view of an the explosive material and the copper liner for the subsequent time moments. The figures show progressive asymmetrical destructions of these elements. The final crushing of the explosive material was approximately $54 \%$ of the volume. 


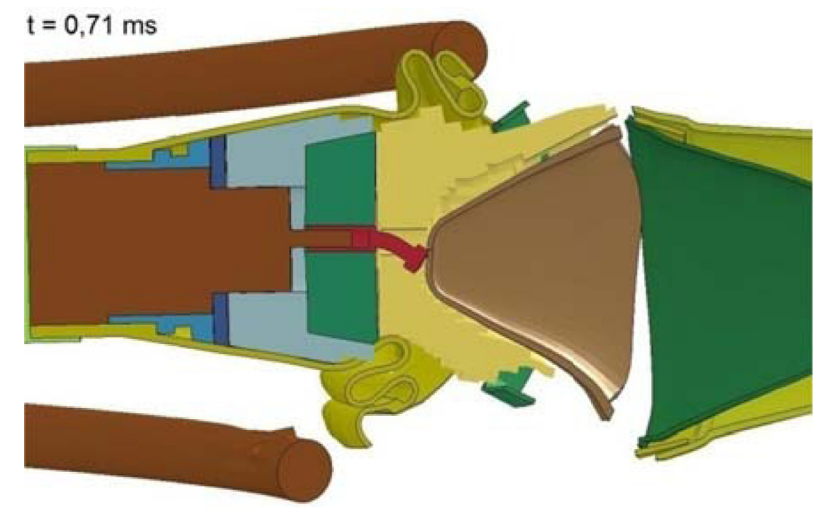

Figure 32: Deformation of the missile for time $t=0,71 \mathrm{~ms}$.

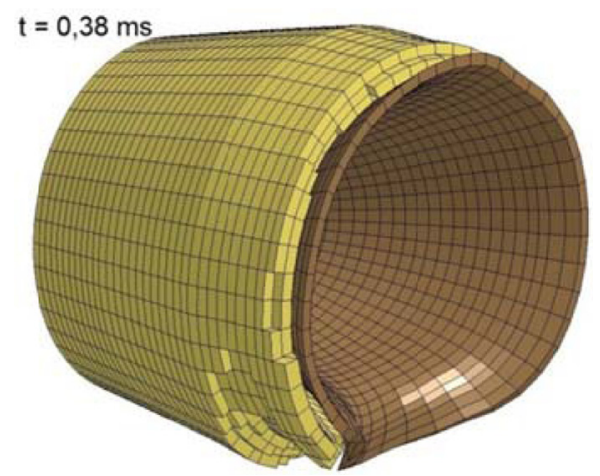

Figure 33: Deformation of the conical liner and the destruction of the explosive material for time $t=0,38 \mathrm{~ms}$.

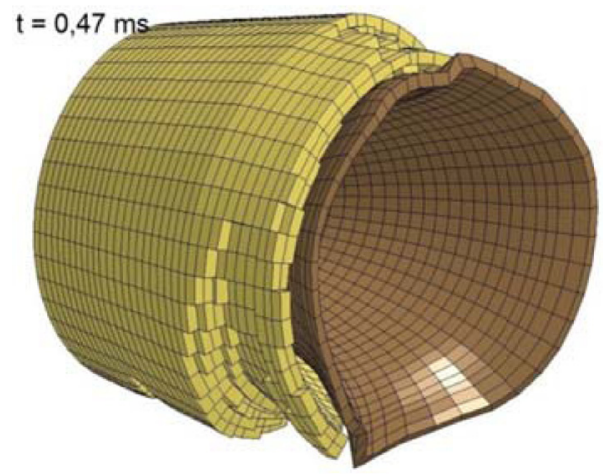

Figure 34: Deformation of the conical liner and the destruction of the explosive material for time $t=0,47 \mathrm{~ms}$. 


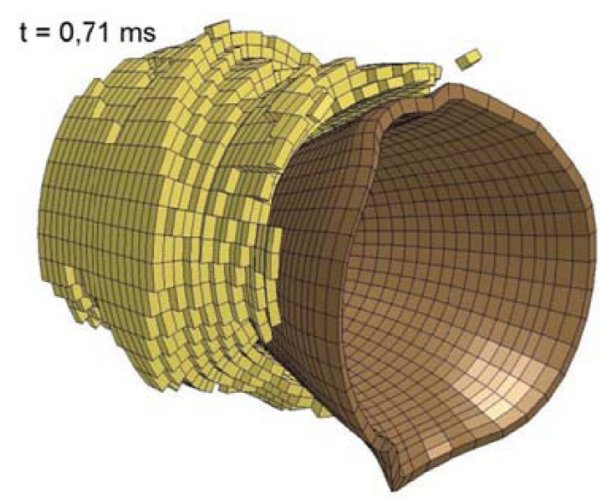

Figure 35: Deformation of the conical liner and the destruction of the explosive material for time $t=0,71 \mathrm{~ms}$.

\section{SUMMARY}

The article presents the results of numerical analyses of the impact of a missile with a cumulative warhead into the rods arranged under different angles in respect to the missile. Behaviour of the explosive material and the cumulative insert were subjected to special analysis. These elements are essential from the perspective of the origin of the cumulative stream which is the main destructive force of this weapon type. The largest and more asymmetrical deformations of these elements are, the slighter the efficiency of the cumulative stream.

On the basis of the conducted analyses, it can be noticed that the impact into the rods rotated in respect to the vertical axis (option 2) causes slighter deformation and destruction of the component elements than the impact into the rods which were not rotated (option 1). However, comparison of option 3 and option 1 shows the increased deformation of the missile. It is caused by a shorter distant between the rods and missile axis.

Adding to the option 3, the rotation around the vertical axis (option 4) caused the decrease in the deformations of the key elements.

On the basis of the presented results, it must be concluded that decreasing of the clearance between the rods and protruding of one of them positively influences the decreasing of the missile efficiency. However, decreasing of the clearance also causes decreasing of probability of armour working. According to principle of operation of the missile, the armour will work only if the fuse does not hit into the rod. In the moment of the impact of the fuse into the obstacle, the piezoelectric element located in it generates the electric impulse initiating the origin of the cumulative stream. The biggest probability of the fuse passage between the rods is obtained when the relation of the fuse to the spacing of the rods is close to zero. However, such situation is not ideal since the distance between the rods could be too significant to damage the missile body and the elements located inside thereby the effects of the armour operation would be minimal. Due to this fact, in the case of rod armours, it is crucial to optimally select the span and the rods diameter.

Figure 37 presents a graph representing a change of probability of effective working of the armour in the function of angle of the rods rotation in respect to the horizontal axis (as in option 3). Figure 36 shows a scheme accepted for calculations of probability of effective working of the armour made of rods with circular cross-section. 


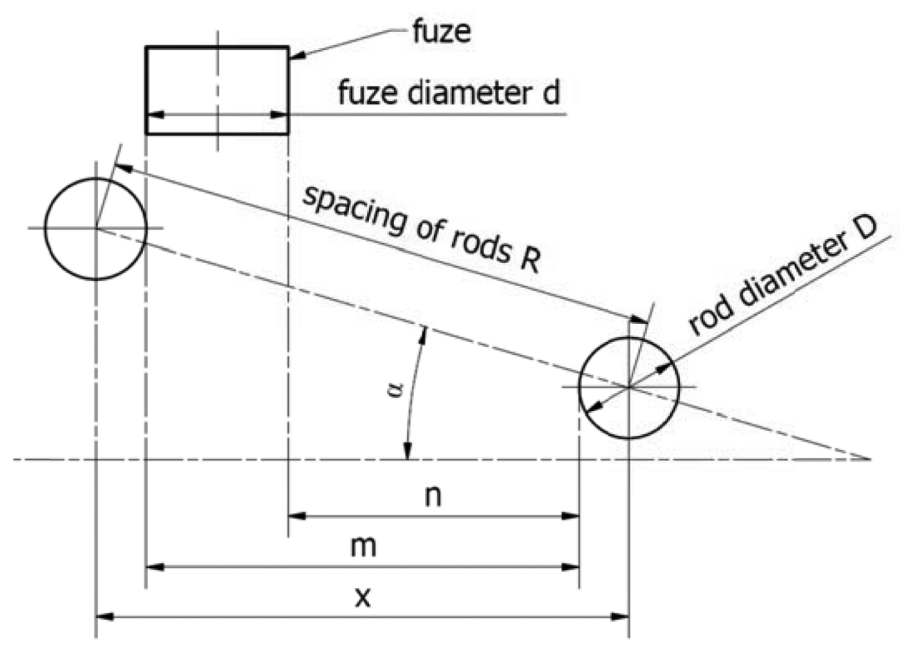

Figure 36: Scheme under which the probability calculations were carried out.

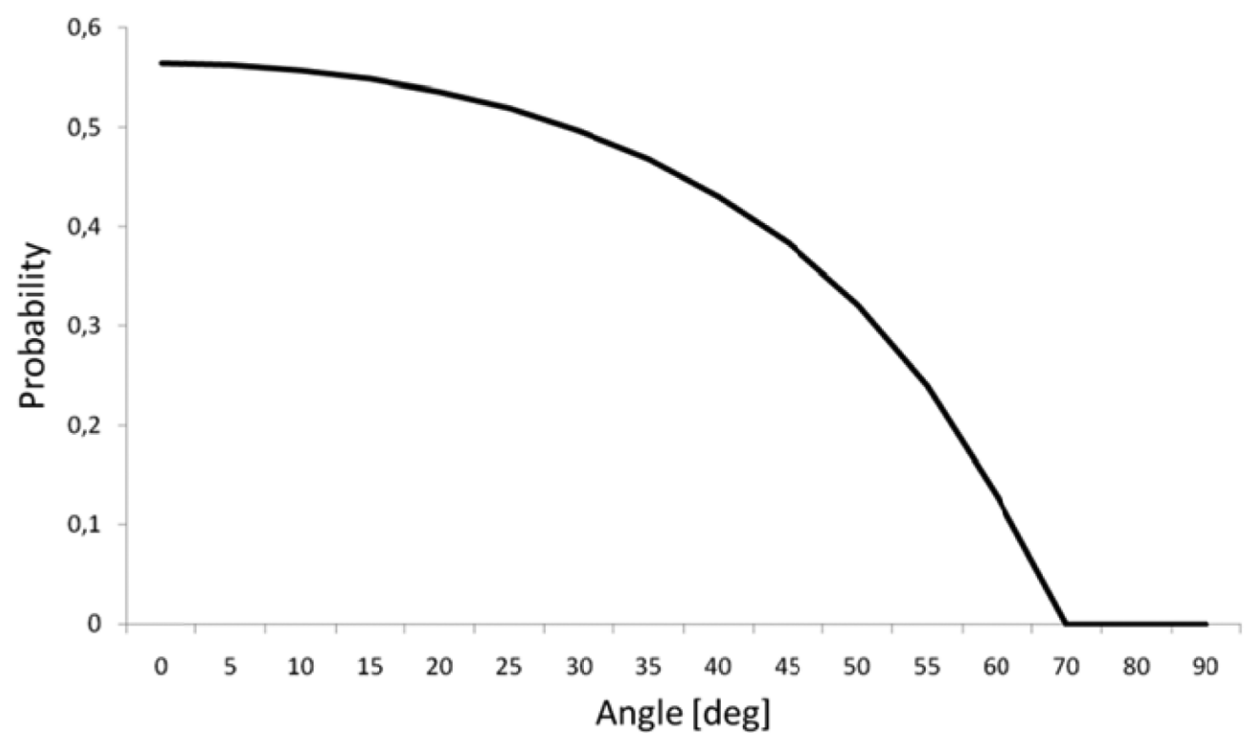

Figure 37: Change of probability of effective working of the armour in the function of angle of the rods rotation in respect to the horizontal axis.

Probability of effective working of an armour of this type is determined by the relation (marking according to Fig. 36):

$$
P=\frac{n}{x}
$$

where

$$
\begin{gathered}
n=m-d=x-D-d \\
x=R \cos \alpha
\end{gathered}
$$


To the calculation the following were taken into consideration:

$$
\begin{aligned}
& R-83 \mathrm{~mm}, \\
& D-15 \mathrm{~mm}, \\
& d-21,2 \mathrm{~mm}
\end{aligned}
$$

According to Fig. 37, maximal probability of effective working of the armour amounts approximately to 0.56 . Along with the growth of angle of rods rotation, the probability decreases and reaches the value 0 for the angle of rotation amounted to $70^{\circ}$.

\section{CONCLUSIONS}

A decisive factor determining the origination of cumulative stream is accuracy of performing the missile as well as its state in the moment of detonation of the explosive material located inside.

From the conducted analyses it can be concluded that at the assumed span of the rods in the options of the impact of the missile with the cumulative warhead into the armour, there occurs a significant deformation of the cumulative insert as well as very large destruction in the area of the explosive material. It guarantees that the cumulative stream is not originated what confirms the efficiency of this kind of a defence mean.

The impact of the missile into the armour rotated in respect to the vertical axis causes deformations of the key elements of the missile, which is an undesirable phenomenon. Nevertheless, it would be worth to perform an analysis of the missile impact under significantly larger angle since in such a case there could occur jam of the missile between the rods or its pushing out outside the armour.

The conducted numerical calculations indicate that along with the decreasing of the clearance between the rods, the damages of the missile increase. Simultaneously, according to the analytical calculations, probability of the passage of the missile between the rods of the fuse decreases. Therefore, optimal selection of the rods diameter as well as their span is important. The presented numerical model allows quick analysing of a number of options of the missile impact and what results in the selection of the best parameters of the armour.

\section{REFERENCES}

[1] Wisniewski, A., Pancerze budowa, projektowanie i badanie, WNT: Warszawa, 2001.

[2] Military Parade, Russia, Moscow, 2001.

[3] Niezgoda, T., Panowicz, R. \& Sybilski, K., Model MES pocisku PG-7G: Wstepna analiza numeryczna uktadu oddziatywania pocisku z przeszkoda, Mechanik, $\mathrm{Nr}$ 7/2010

[4] Jach i inni, K., Modelowanie własnosci dynamicznych ciat metoda punktow swobodnych, PWN: Warszawa, 2001.

[5] Hallaquist, J.O., LS-DYNA. Theoretical Manual, Livermore Software Technology Corporation: California, 2005. 